\title{
MORADIA MÓVEL NO SÉCULO 21: MOTORHOMES ARTESANAIS NO BRASIL ${ }^{1}$
}

\author{
Bárbara Cruz Goulart ${ }^{2}$ \\ Suéllen Mota Marques Costa ${ }^{3}$ \\ Rita de Castro Engler ${ }^{4}$
}

DOI: $10.5752 / P .2316-1752.2020 v 27 n 40 p 208$

\section{Resumo}

Atualmente, a moradia fixa está no centro das discussões sobre habitação brasileira. Contudo, as transformações do século 21 destacam a possibilidade de moradia móvel. Este artigo investiga as relações entre as necessidades de usuários de motorhomes artesanais do tipo Kombi e as alterações executadas por eles. Os resultados revelam que tais ajustes não geraram moradias adequadas. Portanto, elaboraram-se recomendações técnicas

\footnotetext{
1. Este artigo toma por base a monografia desenvolvida como Trabalho de Conclusão do Curso de graduação em Design de Ambientes de autoria de Bárbara Cruz Goulart sob a orientação de Suéllen Mota Marques Costa, aprovada em 2019 na Escola de Design da Universidade do Estado de Minas Gerais (UEMG).

2. Graduada em Design de Ambientes pela UEMG. E-mail: bc.goulart10@gmail.com

3. Técnica em Edificações pelo CEFET-MG, arquiteta e urbanista pela UFMG, mestre e especialista em Construção Civil pela UFMG. Professora na Escola de Design da UEMG. E-mail: suellenmc@hotmail.com.

4. Engenheira Civil pela UFMG, mestre em Engenharia de Produção pela PUC-RJ, especialista (DEA) e, doutora em Engenharia de Produção e Gestão de Inovação Tecnológica pela Ecole Centrale Paris, pós-doutora em Design na UEMG, pós-doutora em Design Social na Ryerson University. Professora na Escola de Design da UEMG. E-mail: rita.engler@gmail.com.
} 
para as alterações, com o intuito de promover a saúde e a qualidade de vida desses moradores viajantes.

Palavras-chave: Moradia. Habitação. Motor - casa. 


\section{MOBILE HOUSING IN THE 21ST CENTURY: HANDMADE MOTORHOMES IN BRAZIL}

\begin{abstract}
Currently, a fixed house is at the center of the Brazilian housing debate. However, the changes of the 21 st century highlight the possibility of mobile housing. This paper investigates the relationship between the needs of Kombi handmade motorhomes users and the changes carried out by them. The results show that such adjustments did not generate suitable housing. Therefore, technical recommendations for changes were developed with the intention of promoting the health and welfare of these traveling residents.
\end{abstract}

Keywords: Home. Housing. Motorhome.
VIVIENDA MÓVIL EN EL SIGLO XXI: AUTOCARAVANAS ARTESANALES EN BRASIL

\section{Resumen}

Actualmente, la vivienda fija está en el centro de las discusiones sobre la vivienda brasileña. Sin embargo, las transformaciones del siglo XXI destacan la posibilidad de la vivienda móvil. Este trabajo investiga la relación entre las necesidades de los usuarios de autocaravanas Kombi artesanales y los cambios que realizan. Los resultados revelan que tales ajustes no generaron una vivienda adecuada. Por lo tanto, se hicieron recomendaciones técnicas para los cambios, con el fin de promover la salud y la calidad de vida de estos residentes viajeros.

Palabras-claves: Casa. Alojamiento. Autocaravana. 


\section{Introdução}

Quando se fala em habitação no Brasil, logo vem à mente uma edificação de caráter fixo. No país, a casa própria aparece no imaginário dos cidadãos como símbolo de estabilidade, segurança e o conforto.

A relação entre a casa e o ser humano é estabelecida pela necessidade de proteção, de modo a garantir a sobrevivência. Ademais, o ser humano tende a construir sua casa de acordo com o momento histórico, social e cultural no qual se encontra (GUTIERREZ, 2008). Tal constatação explica por que alguns povos permaneceram nômades: eles migravam em função de alterações climáticas ou da escassez de recursos para alimentação.

Durante o período de 1930 a 1964, houve no Brasil diversas iniciativas para a construção de residências, cujo resultado foi o surgimento de grandes edifícios de apartamentos (BRUNA, 2015). O desejo de morar próximo ao local de trabalho e o crescente valor do solo urbano, pouco a pouco, estabeleceram o apartamento como principal alternativa para residência nas metrópoles.

Todavia, a partir do final do século 20, os avanços tecnológicos nas telecomunicações apontaram para novas relações de trabalho. A expansão das redes de comunicação sem fio sinalizava a possibilidade de trabalhar em qualquer lugar. Inclusive, em muitos casos, a mobilidade 
é uma necessidade. As tecnologias disruptivas surgem e transformam rapidamente os cenários econômicos, provocando a célere ruína de grandes empresas. Consequentemente, empresários e trabalhadores precisam realizar uma adaptação veloz: em termos de qualificações, abordagens e localização no espaço.

As migrações que em tempos remotos foram motivadas por recursos animais e vegetais permanecem na contemporaneidade, haja vista que tais recursos equivalem ao trabalho. Tal contexto faz lembrar o filósofo Heráclito de Éfeso (504-501 a.C.), o qual menciona a incessante mutabilidade do universo (GUTIERREZ, 2008).

\begin{abstract}
A "fluidez" heraclitiana, a Panta Rei, serve de agasalho para as teses contemporâneas de mobilidade veloz e consequente instabilidade das relações sociais, do emprego, dos bens, e inclusive, da moradia e, com efeito, da arquitetura. O sólido torna-se líquido, o líquido flui, é a "modernidade líquida" de Zygmund Bauman (GUTIERREZ, 2008, p.64, grifos do autor).
\end{abstract}

No início do século 21, a noção de estabilidade apresenta-se ainda mais fragilizada. No entanto, as edificações residenciais permanecem estagnadas em meio de uma sociedade líquida. Apartamentos padronizados tentam fixar no espaço populações, enquanto a tecnologia abre caminho para a flexibilidade, a adaptação e a mobilidade.

Ainda pouco estudada no Brasil, a residência em veículos apresenta-se como possível alternativa para o modo de 
vida contemporâneo e, de fato, existem grupos sociais que optaram por essa modalidade no país. Embora diversificada, pode-se destacar algumas características dessa população: casais de aposentados que optaram por essa moradia móvel após a independência dos filhos; jovens recém-casados que decidiram morar em veículos para viajar após o matrimônio e, por fim, viajantes solteiros, cujo trabalho é compatível com motorhomes, como artesãos que comercializam seus produtos nas praias do país. Também se verifica a existência de pessoas que moram em motorhomes temporariamente (apenas para viajar), como também há quem utilize seu veículo como moradia permanente. Ao contrário do que acontece em países como os Estados Unidos, devido à pobreza extrema, não foram encontradas informações sobre brasileiros que moram em veículos, possivelmente pelo alto custo dos automóveis no Brasil.

Santos e Almeida (2017) estudaram o uso do motorhomes e trailers na região Sul do Brasil, apresentando informações importantes sobre o perfil desses moradores. No entanto, são raros os estudos sobre essa prática em outras regiões do país.

Em investigações preliminares, esta pesquisa identificou grupos sociais provenientes do município de Belo Horizonte, estado de Minas Gerais, os quais fazem usos de motorhomes artesanais, especificamente veículos do 
tipo Kombi, adaptados para moradia pelos próprios usuários. A pesquisa dedicou-se à investigação das relações entre as necessidades desses usuários e as adaptações feitas por eles. Para tanto, elaborou-se referencial teórico, a qual abarcou conceitos fundamentais, uso de motorhomes no Brasil e aspectos jurídicos do país com relação ao tema. Em seguida, foi elaborada entrevista online com os usuários, com o intuito de identificar as necessidades e as alterações feitas. Posteriormente, procedeu-se ao tratamento e à análise dos dados. Os resultados revelaram que os ajustes realizados nos veículos por seus usuários não resultaram em moradias adequadas. Consequentemente, foram elaboradas recomendações técnicas no âmbito do design de ambientes para melhoria da qualidade ambiental.

Gil (2002), define pesquisa descritiva como aquela cujo objetivo primordial é descrição das características de determinada população ou o estabelecimento de relações entre variáveis. Em consonância com essa definição, classifica-se esta pesquisa como descritiva, cujas amostras são por conveniência ou acessibilidade (não probabilística). 


\section{Carro e casa: o campismo e a moradia móvel no Brasil}

Antes de abordar a moradia móvel, convém estabelecer diferenças entre os termos casa, moradia, habitação e domicílio, pois tratam-se de conceitos fundamentais para o estudo do tema.

O vocábulo casa remete ao invólucro físico que protege o ser humano, também podendo ser caracterizado como mercadoria. Por sua vez, o termo moradia compreende a relação entre o ente físico e os(as) usuários(as). Já o termo habitação deve ser entendido como sendo a moradia e a casa interligadas ao espaço urbano (GUTIERREZ, 2008).

Segundo Gutierrez (2008), a noção de domicílio deriva da necessidade de fixar o indivíduo em um determinado local, onde ele possa exercer seus direitos e responder por seus deveres jurídicos. O Código Civil Brasileiro estabelece em seu artigo 70 que o domicílio é o lugar em que uma pessoa reside em caráter definitivo (BRASIL, 2002). A necessidade legal de moradia fixa é um dos grandes empecilhos enfrentados por grupos sociais que desejam morar exclusivamente em veículos, conforme será detaIhado mais adiante.

Quando se fala em moradia móvel, é conveniente distinguir dois tipos principais: o trailer e o motorhome. De 
acordo com Gutierrez (2008), o trailer pode ser desmembrado da parte do veículo que produz a tração; por outro lado o motorhome é construído de modo fixo a um determinado automóvel.

O Código de Trânsito Brasileiro apresenta a seguinte definição, em seu Anexo I: "MOTOR-CASA (MOTOR-HOME) veículo automotor cuja carroçaria seja fechada e destinada a alojamento, escritório, comércio ou finalidades análogas (BRASIL, 1997, n.p.)

Ao pesquisar a história dos motorhomes no Brasil, uma das primeiras constatações é a carência de estudos científicos profundos sobre o tema. A própria mobilidade dos usuários, bem como a dificuldade deles em obter acesso às redes de telecomunicações, dificulta a elaboração de pesquisas detalhadas. Consequentemente, muitas vezes é preciso recorrer a websites de fabricantes de equipamentos, associações de campistas ou mesmo blogs dedicados ao tema para obter informações sobre esse modo de morar. Como exemplo, a dissertação de Gutierrez (2008) e a monografia de especialização de Salgueiro (2016) citam o portal MaCamp como uma das referências.

Santos e Almeida (2017) estudaram os motorhomes no âmbito do turismo e associam-nos ao campismo. Segundo Palhares (2002) apud Santos e Almeida (2017): os motorhomes necessitam da infraestrutura de campings 
para atividades como abastecimento de água e energia elétrica, bem como para garantir um pernoite com maior segurança aos usuários.

Em 1965, surgiu em Novo Hamburgo, estado do Rio Grande do Sul, a Turiscar, empresa nacional produtora de trailers e motorhomes (SANTOS e ALMEIDA, 2017). Tal fato leva a crer que, na década de 1960, existia demanda para compra e uso desse tipo de veículo no Brasil. Contudo, segundo Solha (2002) foi somente na década de 1970 que o uso de motorhomes no país se intensificou em virtude da expansão da malha rodoviária nacional, uma vez que as novas estradas facilitaram o acesso a destinos pouco conhecidos.

Após um período de sucesso, a Turiscar decretou falência no final da década de 1990. Nessa época, houve uma alteração na legislação de trânsito brasileira que impactaria o uso de trailer. O novo Código de Trânsito Brasileiro, publicado em 1997, passa a exigir do condutor de trailers habilitação na categoria E. A partir desse momento, um grande número de usuários preferiram deixar seus trailers fixos em acampamentos, referindo-se a eles como rodas quadradas. Alguns anos mais tarde, a Lei n ${ }^{\circ} 12.452$, de 21 de julho de 2011, alterou o inciso $V$ do artigo 143 do Código de Trânsito Brasileiro e a habilitação tipo E passou a ser exigida apenas para trailers com mais de 6.000 quilogramas. (SANTOS e ALMEIDA, 2017). 
Com relação aos motorhomes, a Lei $n^{\circ} 12.452$, de 21 de julho de 2011, permite a condução de motorhomes por motoristas habilitados na categoria $B$, desde que o peso do veículo não exceda a 6.000 kg, ou cuja lotação não exceda a 8 (oito) lugares (BRASIL, 2011). No que se refere a esse assunto, Salgueiro (2016, p.18) afirma que "no projeto de interiores, cabe ao designer especificar materiais mais leves para atingir esse objetivo, e consequentemente pensar em outros detalhes, pois um carro mais leve economiza combustível e é menos poluente".

Atualmente, conforme afirmam Santos e Almeida (2017), existem empresas destinadas à produção de trailers e motorhomes nos estados de São Paulo, Santa Catarina e Rio Grande do Sul. Segundo suas pesquisas, o hábito de viajar em trailers e motorhomes é mais comum na região sul do país e, no que diz respeito o perfil dos usuários brasileiros pesquisados, os autores notaram que a maioria dos entrevistados possuíam mais de 50 anos. Além disso, citam esse tipo de viagem como uma evolução natural do campismo, haja vista o maior conforto que o veículo oferece em relação as barracas. Ademais, a liberdade de destino e a possibilidade de socialização é um atrativo para pessoas nessa faixa etária. A pesquisa também revelou a existência de usuários que moram em veículos de modo permanente. 


\section{Aspectos jurídicos dos motorhomes no Brasil}

Viver em motorhome permanentemente restringe 0 acesso a serviços, como por exemplo, fornecimento de internet, visto a dificuldade de localizar o usuário para cobranças. Ainda, para obtenção de elevadas velocidades de transmissão de dados é preciso dispor de infraestrutura cabeada e, portanto, fixa, como redes de fibra ótica, por exemplo.

Outro desafio de ordem jurídica para os moradores de motorhomes no Brasil refere-se ao licenciamento urbanístico. Antes de construir uma edificação (fixa), é necessário requerer autorização aos órgãos públicos municipais. Na ocasião, avaliam-se diversos aspectos referentes ao território. Todavia, as casas móveis podem ser desvinculadas do solo, escapando à supervisão do município (GUTIERREZ, 2008).

A Resolução 743 do Conselho Nacional de Trânsito (CONTRAN), publicada em 23 de novembro de 2018, estabelece requisitos técnicos para modificação ou transformação de veículos para motor-casa, assim como sua circulação e fiscalização (CONSELHO NACIONAL DE TRÂNSITO, 2018).

Art. $3^{\circ}$ Toda modificação ou transformação realizada em veículos para tipo motorcasa deve ser precedida apenas da obtenção do Certificado de Segurança Veicular (CSV), nos termos da Resolução CONTRAN nº 292/08, 
ou sucedâneas, além de:

I - A modificação deverá respeitar os pesos e capacidades previstos pelo fabricante do veículo utilizado como base, além dos pesos e dimensões previstos na Resolução CONTRAN n² 210/2006, ou sucedâneas;

II - Não devem existir equipamentos, acessórios ou objetos soltos dentro do habitáculo do veículo, que apresentem risco de lesões para os ocupantes do veículo;

III - Não devem existir equipamentos, acessórios ou objetos que atrapalhem o campo de visibilidade à frente do condutor e o campo de visão dos retrovisores externos (CONSELHO NACIONAL DE TRÂNSITO, 2018, s/p).

A Resolução CONTRAN 743 estabelece ainda que, quando o motor-casa estiver em movimento, todos os ocupantes devem estar alocados em assentos e com cintos de segurança. Ademais, não é permitido transporte de bagagens e equipamentos na parte superior do veículo (CONSELHO NACIONAL DE TRÂNSITO, 2018).

A seu turno, a Resolução CONTRAN 292, de 29 de agosto de 2008, determina em seu artigo quarto que as modificações em veículo devem ser precedidas de inspeção de segurança veicular conforme legislação específica do Instituto Nacional de Metrologia, Qualidade e Tecnologia (INMETRO). Caso aprovado, será gerado para o veículo o Certificado de Segurança Veicular (CSV) (CONSELHO NACIONAL DE TRÂNSITO, 2008).

Nota-se, portanto, a ausência de integração entre a le- 
gislação urbanística e a legislação de trânsito. Convém também considerar os campings, pois são importantes locais de acesso a infraestrutura (água potável, esgoto, etc.) para os usuários de motorhomes. Em outras palavras, a legislação deveria contemplar os aspectos casa, veículo e habitação relativos aos motorhomes.

\section{Usuários de motorhome do tipo kombi com origem em Belo Horizonte}

Nesta pesquisa, foram entrevistados sete usuários de motorhome artesanal (em veículo do tipo Kombi) provenientes do município de Belo Horizonte, por meio do Google Forms, plataforma de geração de questionários online disponibilizadas pelo Google (2019). O reduzido número de entrevistados se deve à mobilidade constante e acesso restrito à internet por parte desses sujeitos, o que dificulta o contato. Os questionários foram preenchidos pelos entrevistados no segundo semestre de 2019.

Optou-se por dezessete perguntas, contemplando tanto questões objetivas quanto discursivas. Os questionamentos foram divididos em três categorias: perfil dos usuários, adaptações realizadas no veículo e adaptações não realizadas. O primeiro grupo inquiriu sobre faixa etária; período de tempo no qual mora no veículo; uso do motorhome como moradia permanente ou temporária e execução de adaptações no veículo. O segundo grupo de 
questões tratou sobre o suporte técnico para as modificações e o grau de importância dos ajustes desejados. Por fim, o terceiro grupo questionou os entrevistados sobre alterações não realizadas; razões que impediram a execução e alternativas empregadas para higiene pessoal.

A pesquisa revelou que a $57 \%$ dos entrevistados situam-se na faixa de 25 a 30 anos, $29 \%$ possuem entre 30 e 35 anos e $14 \%$ possuem entre 35 e 40 anos. Ademais, $100 \%$ dos entrevistados informaram que utilizam o motorhome como moradia permanente. Desse total, 57\% habitam o veículo entre 2 e 3 anos, 29\% há menos de 1 ano e 14\% moram no motorhome há mais de 4 anos.

Com relação às modificações no veículo, 100\% dos entrevistados realizaram alterações, sendo que $43 \%$ contaram com a assistência de um mecânico, 29\%, com a ajuda de um pintor, $14 \%$ receberam colaboração de familiares e $14 \%$ não responderam. Além disso, as adaptações consideradas mais importantes foram instalação de sistema de energia elétrica, de fogão e de geladeira.

Quando questionados sobre as modificações não executadas, houve resposta de apenas $43 \%$ dos entrevistados. Desse percentual, 33\% não instalaram sistema de energia elétrica, trazendo como justificativa o alto custo. Por sua vez, 67\% afirmaram não instalar rede de internet de alta e média velocidade e justificaram que a internet 
móvel (disponível no aparelho celular) é suficiente para atender às necessidades.

Contudo, quando questionados sobre a higiene pessoal, 43\% dos entrevistados afirmaram utilizar sanitários em estabelecimentos comerciais; $14 \%$ afirmaram utilizar banheiros disponíveis em campings; $29 \%$ informaram possuir banheiro pessoal e 14\% não responderam.

Com relação ao perfil dos usuários, a pesquisa revelou que a maioria deles é jovem ( 25 a 30 anos) e todos utilizam o veículo como moradia permanente, apesar de poucos estenderem essa prática por mais de 4 anos. Todavia, há indícios de que moram em condições insalubres, pois grande parte deles não possui instalações hidrossanitárias no veículo. Outro fator é a falta de sistema de energia elétrica, que dificulta o uso de geladeira, eletrodoméstico muito importante para manter a qualidade dos alimentos. Por fim, a carência de uma assistência técnica mais ampla expõe os moradores a diversos riscos, como incêndios, problemas posturais, etc.

Sendo assim, constata-se que necessidades básicas de higiene (como acesso a água potável, saneamento básico e refrigeração dos alimentos) não foram plenamente atendidas por meio das alterações nos veículos feitas por eles. Logo, a atuação expressiva de profissionais ligados ao projeto de ambientes se faz necessária para garantir a 
saúde e qualidade de vida dessa população, bem como para evitar a proliferação de doenças pelo território nacional.

\section{Recomendações técnicas: energia elétrica, fogão e geladeira}

Para geração de energia elétrica, é possível utilizar placas fotovoltaicas instaladas no teto do veículo. No entanto, deve-se atender à Resolução CONTRAN 743, que proíbe o transporte de bagagens e equipamentos no teto do motorhome. Nesse caso, a primeira opção é retirar a placa do teto antes do veículo entrar em movimento. A segunda alternativa consiste em fixar a placa de modo que não ofereça risco de queda de modo que a placa não seja caracterizada como equipamento em transporte, garantindo também a segurança dos outros motoristas. Como a placa é fina e leve, se bem fixada, a possibilidade de desprendimento é reduzida. Convém lembrar que a transformação de veículo para motorhome requer inspeção de segurança veicular, em conformidade com a Resolução CONTRAN 292.

Outro aspecto muito importante com relação às placas fotovoltaicas consiste em evitar seu furto. Por ser um dispositivo de elevado valor, deve-se projetar mecanismos para impedir sua remoção ou para escondê-la. Alguns hábitos dos usuários, como pernoitar em campings em 
detrimento de locais isolados, também podem aumentar a segurança.

Também deve-se evitar a instalação de fios no exterior do veículo, mas caso ocorra, eles devem adequadamente fixados, isolados e protegidos das intempéries. Caso sejam necessários pequenos furos no veículo para passagem de fiação, esses devem garantir estanqueidade face à incidência de águas pluviais.

A bateria deve ser instalada no interior do veículo, o mais próximo possível da placa, para evitar perda de carga. Além de tudo, é necessário um equipamento capaz de converter a voltagem da bateria (geralmente 12 Volts) para a voltagem requerida pelos equipamentos, como por exemplo, 220 Volts. Evidentemente, é fundamental escoIher equipamentos (lâmpadas, fogão elétrico, geladeira, etc.) cuja tensão de funcionamento seja compatível com a fornecida pelo sistema.

Convém notar que os equipamentos do sistema de geração de energia elétrica são potencialmente fontes de calor e que devem dissipar essa energia térmica para o entorno, de modo a garantir o seu correto funcionamento. Logo, os equipamentos necessitam estar em áreas ventiladas, mas estanques à água e protegidos da entrada de animais. $\mathrm{O}(\mathrm{a})$ projetista também deve controlar esse ganho de calor no interior do veículo, prevendo mecanismos 
de climatização preferencialmente naturais, como a ventilação cruzada. É preciso também checar com o fabricante a potência limite que o sistema consegue alimentar. $O$ somatório da potência dos equipamentos instalados deve resultar em valor inferior a esse limite.

Com exceção da placa geradora de energia, todos os equipamentos devem estar localizados no interior do veículo, em local seco e devidamente fixados, de modo que não alterem a sua posição quando o motorhome entrar em movimento. Requer se também prever fácil acesso para manutenção. Além disso, os controladores dos equipamentos carecem de estar visíveis e ser de fácil acesso e manuseio pelos usuários. Como as instalações elétricas são possíveis focos de incêndio, é primordial evitar a proximidade com materiais inflamáveis.

O uso de fogão a gás em motorhomes não é recomendado, haja vista o risco de explosão e incêndio. Ademais, por ser um produto perigoso, o transporte do botijão de gás está sujeito a restrições pela legislação brasileira. Logo, recomenda-se uso de fogões elétricos (com aquecimento por resistor elétrico ou por indução eletromagnética). Tais equipamentos, além de dispensarem o uso de gás, não produzem chama e, portanto, são mais seguros. O local onde ocorre o preparo dos alimentos também deve pos- 
sibilitar rápida exaustão do calor, gases e umidade típicos do processo de cocção. Os projetistas devem garantir que tal circulação do ar possa ocorrer mesmo em dias chuvosos.

No tocante à geladeira, deve-se optar por modelos frostfree, que não requerem degelo para limpeza, de forma que se evite a geração de umidade no interior do veículo, uma vez que a umidade favorece a proliferação de microrganismos, aumenta o risco de curto-circuito e acelera a deterioração de diversos materiais. Por serem menores e mais leves, geladeiras compactas e frigobares devem ser usados sempre que forem capazes de comportar a quantidade necessária de alimentos.

\subsection{Instalações hidrossanitárias}

Para garantia da higiene, existe no mercado um vaso sanitário químico transportável (Figura 1). Por seu tamanho reduzido e por dispensar tubulações, ele pode ser alocado sob algum móvel do motorhome, conforme mostra a Figura 2. 


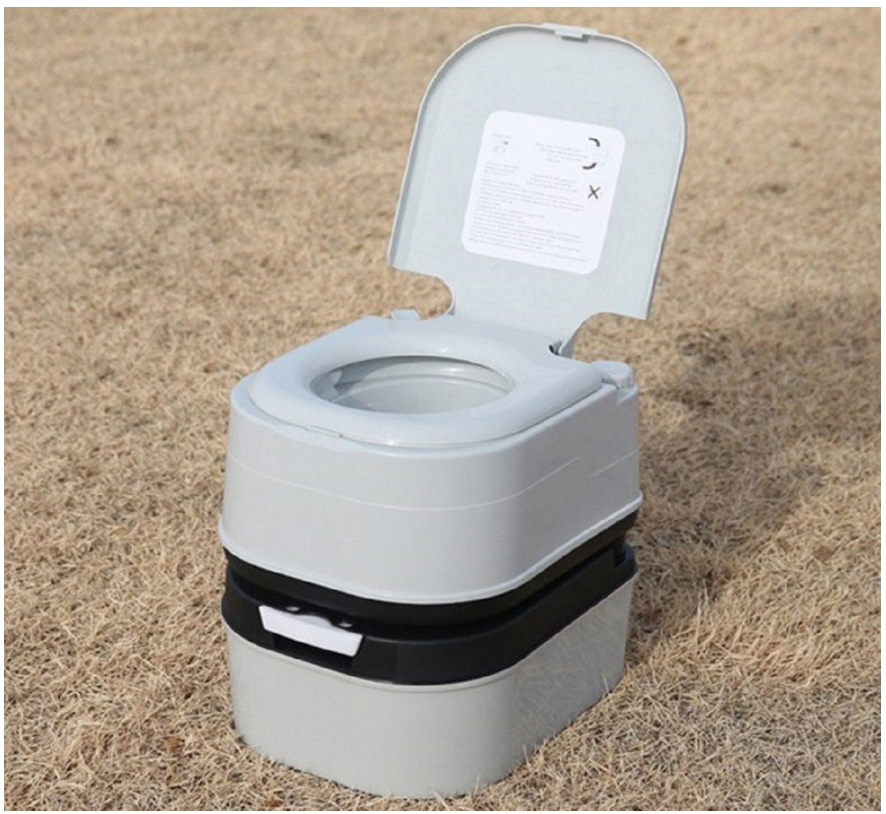

Figura 1 | Sanitário químico portátil para uso em motorhomes artesanais. Fonte: BLUE CAMPING, $2020^{5}$.

5. Como a fonte consiste em um website, não foi possível indicar o ano com precisão. Logo, indicou-se o ano provável entre colchetes e com ponto de interrogação, em conformidade com as recomendações da NBR 6023:2018, p.44. O mesmo ocorreu em outras figuras deste artigo, por razões similares. 


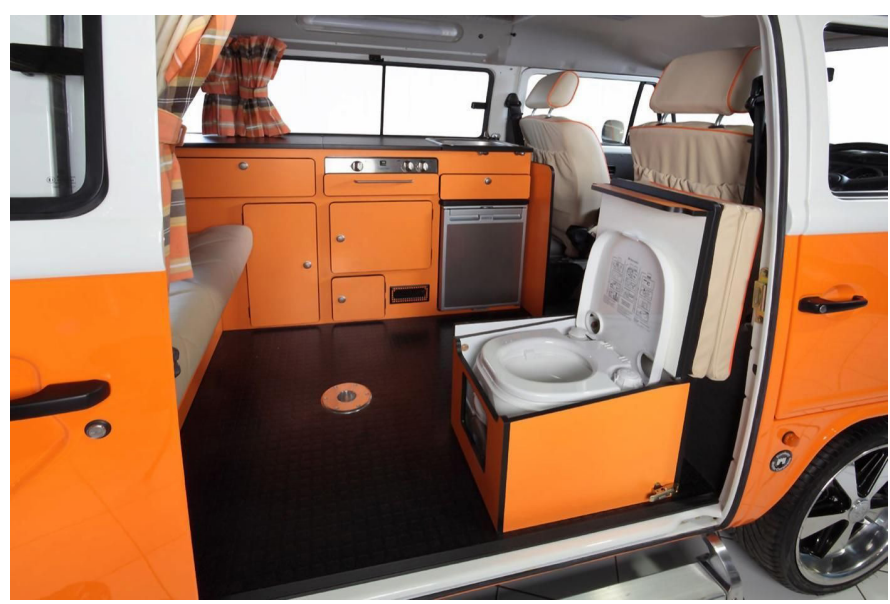

Figura 2 | Sanitário químico portátil instalado em motorhome. Fonte: CIRIACO, 2018. 
O referido sanitário portátil possui dois recipientes para líquidos. O primeiro é destinado ao acionamento manual da descarga. Tal reservatório deve ser preenchido como água limpa juntamente ao líquido recomendado pelo fabricante. O objetivo nesse caso é a limpeza e remoção de odores da bacia sanitária. O segundo recipiente, situado abaixo da bacia, destina-se ao recebimento de efluentes. Nesse segundo reservatório também deve ser adicionado o líquido específico, para redução dos odores, de modo a possibilitar o armazenamento dos efluentes por algum tempo. Quando os viajantes estiverem em local com rede de esgoto, o recipiente inferior deve ser removido e os dejetos podem ser descartados dentro do um vaso sanitário comum. Feito isso, deve-se proceder à limpeza do reservatório, em conformidade com as recomendações do fabricante. Embora a recomendação do fabricante seja o descarte dos efluentes com o redutor de odores na rede de esgoto tradicional, os impactos ambientais desse procedimento ainda são pouco conhecidos.

Além disso, recomenda-se instalar reservatório de água com bomba hidráulica, capaz de alimentar ducha de banho e pia da cozinha, esta que também serve como lavatório em muitos casos.

Com relação ao reservatório de água, é possível colocar tampa com chave no ponto de abastecimento, que é similar à tampa de abastecimento do tanque de combus- 
tível dos veículos comuns. Isso evita a ação de vândalos e garante a qualidade da água de uso dos viajantes. Outro ponto importante é a necessidade da tubulação de alimentação do tanque ser de diâmetro maior do que a das mangueiras de uso corrente no mercado. Ainda, deve ser prevista outra tubulação para retirada do ar do tanque, de modo que a água possa entrar. Também, os usuários devem controlar o nível da água no reservatório para evitar transbordamento e escassez. Em casos mais sofisticados, tal controle pode ser feito por um sensor com alimentação elétrica (BRAZIL OF GRID, 2018).

No que concerne à bomba, essa deve garantir a pressão hidráulica adequada para as atividades. É essencial garantir que, assim que a torneira da pia ou a ducha de banho seja acionada, a bomba hidráulica seja também ativada de forma que seja garantido o fluxo de água com a pressão satisfatória.

No tocante ao aquecimento da água, é possível instalar um boiler. Desse modo, é possível garantir água quente para o banho (BRAZIL OF GRID, 2018). Tanto o tanque quanto o boiler podem ser locados sob a cama do motorhome, para que facilite sua manutenção.

O mais comum é que o banho ocorra na área externa do veículo, com uso de ducha manual e cortina plástica, conforme mostra a Figura 3. 


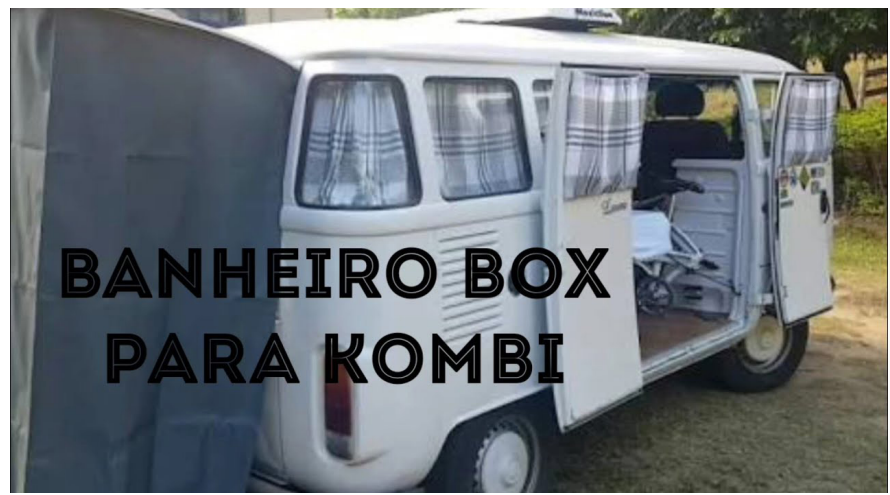

Figura 3 | Área para banho na parte posterior externa do veículo.

Fonte: DE KOMBI POR AÍ, 2017.

Existem, ainda, os tanques para armazenamento do esgoto oriundos do banho. Contudo, frequentemente as águas servidas são descartadas diretamente sobre o solo, considerando o volume de líquido a ser contido. Atentando à poluição gerada, tal descuido com os efluentes pode ser considerado um ponto negativo, sendo necessária a elaboração de melhores soluções técnicas. No que Ihe diz respeito, para o esgoto da pia de cozinha é previsto um tanque, o qual deve ser esvaziado em local apropriado. Assim como nas moradias fixas, não ocorre mistura de esgoto primário com secundário, dadas as diferenças entre os efluentes. Logo, cada um deles possui reservatório próprio. 
Portanto, a criação de sistemas hirossanitários em motorhomes artesanais não é apenas possível, como também, extremamente necessária. Como esses moradores estão em trânsito constante, é fundamental garantir acesso à água limpa e ao saneamento básico para evitar que essas pessoas transmitam doenças de uma comunidade para a outra. Mais um cuidado importante consiste em reduzir impactos ambientais, descartando efluentes em locais corretos. Sendo assim, considera-se que, por se tratar de uma questão de saúde pública, deveria haver ações específicas que preservem aos moradores viajantes condições de higiene satisfatórias.

\subsection{Outros pontos para garantia da saúde e qualidade de vida}

A falta de espaço, a variação de temperatura e a presença de mosquitos são problemas que podem ser solucionados com o devido design de mobiliário.

Recomenda-se favorecer a ventilação cruzada por meio de aberturas para garantia do conforto térmico e da qualidade do ar. O uso de sistemas de climatização artificial é possível, contudo, muitas vezes, os usuários desejam contato com o exterior, o que pode inviabilizar o uso do equipamento.

Considerando a possibilidade de baixas temperaturas, também é possível realizar isolamento térmico com man- 
tas específicas aplicadas sobre a face interna da envoltória metálica do veículo. Além disso, é viável instalar telas mosquiteiro nas janelas e portas para evitar a entrada de insetos.

Com relação ao mobiliário, recomenda-se que o design tenha como diretriz o adequado aproveitamento do espaço interno. Por exemplo, o uso de cama dobrável (Figuras 4 e 5) dispensa o uso de sofá. Inclusive, o uso de elementos projetáveis sobre a área externa (Figuras 6 e 7), ampliam da área útil da moradia, da mesma maneira que favorecem o contato dos usuários com o exterior.

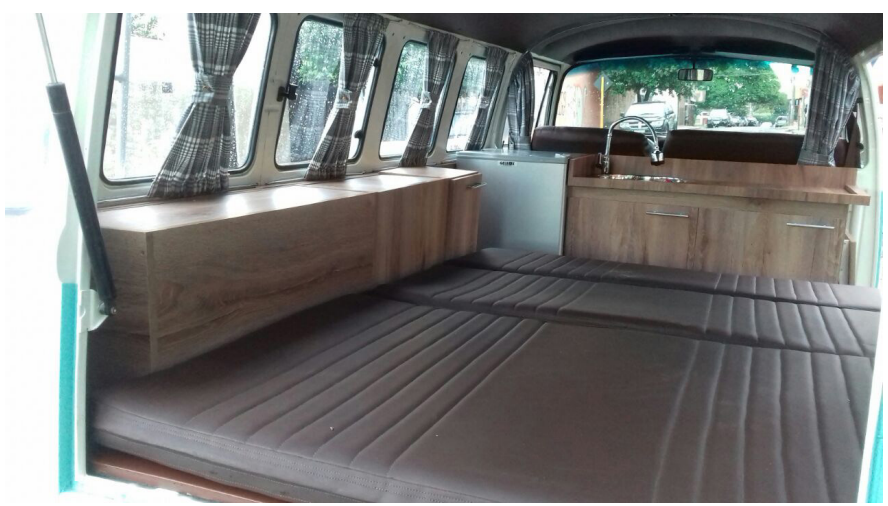

Figura 4 | Cama retrátil (próxima à pia) sendo usada como cama. Fonte: RIO BIKE, 2020. 


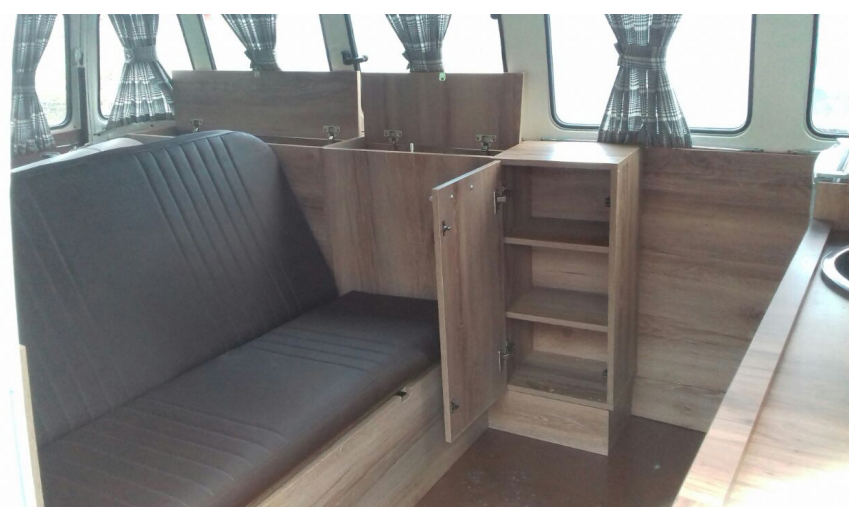

Figura 5 | Cama retrátil sendo usada como sofá. Fonte: RIO BIKE, 2020.

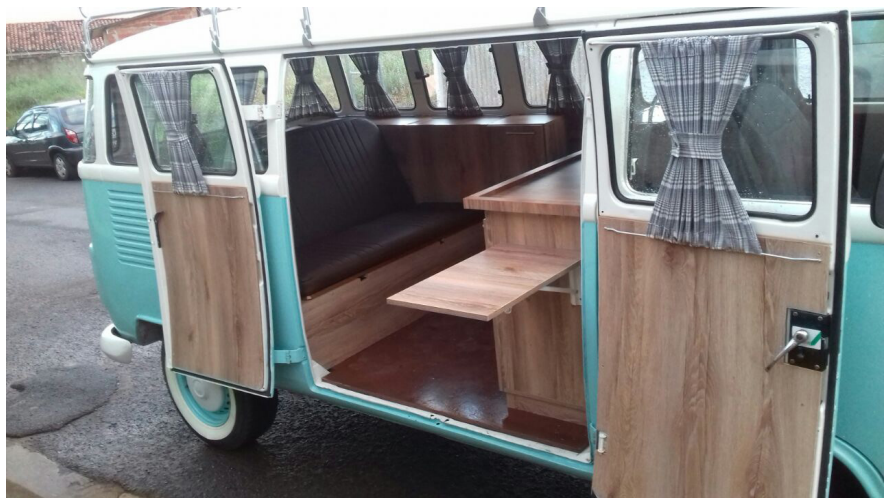

Figura 6 | Mesa projetando-se sobre a área externa.

Fonte: RIO BIKE, 2020. 


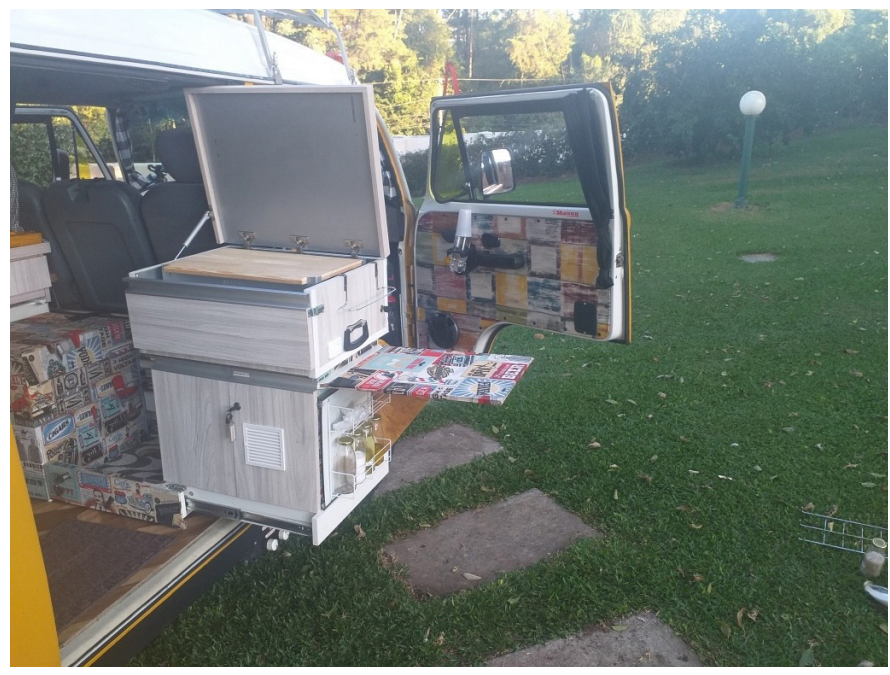

Figura 7 | Móvel extensível para ampliação da área útil. Fonte: CASSULA, $2018^{6}$

É também importante ressaltar que os objetos não podem cair durante os deslocamentos. Em vista disso, as portas dos armários devem possuir dispositivos de travamento (Figura 5). Por outro lado, para objetos leves, como lençóis, pode-se utilizar cordas elásticas e telas. Os objetos não devem ficar soltos dentro dos armários, de modo a poupar ruídos indesejáveis.

6. Como a fonte consiste em um website, não foi possível indicar o ano com precisão. Logo, indicou-se a década certa entre colchetes e com hífen, em conformidade com as recomendaçōes da NBR 6023:2018, p. 44. 
Para melhorar a circulação de ar no interior do veículo, recomenda-se que os móveis tenham dispositivos que favoreçam a ventilação cruzada, como painéis de chapa perfurada ou telas. Isso evita que os objetos adquiram mofo, prevenindo doenças respiratórias.

\section{Considerações finais}

O contexto de mutabilidade do início do século 21 convida a investigação das moradias móveis. Em consonância com essa diretriz, a pesquisa revelou pessoas que moram em motorhomes artesanais permanentemente, mas em condições inadequadas. A construção de rede elétrica instalação de fogão e geladeira, bem como o provimento de instalações hidrossanitárias são os principais aspectos a serem melhorados, de modo a garantir a saúde e a qualidade de vida dessa população.

No entanto, muito ainda precisa ser feito para a garantia do direito à moradia digna aos moradores viajantes. Muitas das soluções técnicas recomendadas, como o uso de fogões elétricos, placas fotovoltaicas e sistemas hidrossanitários são de alto custo. Logo, seria necessário dispor de alternativas de financiamento e/ou de subsídios para aquisição e instalação dos sistemas e equipamentos. Ademais, seria necessário assegurar ao longo das estradas brasileiras a adequada infraestrutura de campings, de forma que os viajantes possam obter segurança e acesso 
às redes de água potável e esgotamento sanitário adequado. Do ponto de vista jurídico, instrumentos legais precisam ser desenvolvidos com foco nesse grupo social, para que possam exercer a sua cidadania, apesar da mobilidade de seu domicílio.

É preciso dar visibilidade aos moradores de motorhomes artesanais brasileiros no cenário da habitação contemporânea. A mobilidade e dificuldade de acesso à internet dessa população é um grande desafio tanto para a coleta quanto para a comprovação de dados. Portanto, deve-se incentivar a elaboração de estudos sobre o tema. Esforços devem ser feitos para conhecer em profundidade essa forma de morar, pois assim como a moradia fixa, a moradia móvel deve ser amparada por políticas públicas específicas. $O$ direito à moradia digna deve alcançar a todos, por meio de um tratamento equânime, que considere as diferenças e garanta qualidade de vida aos diversos grupos que compõem a sociedade.

\section{Referências}

BLUE CAMPING. Vaso/Privada Portátil Porta Potti 24L

PLUS. [S.I.], [2020]. Disponível em: https://www.bluecamping.com.br/privada-portatil-porta-potti-24l. Acesso em: 27 maio. 2020. 
BRASIL. Lei $\mathbf{n}^{\circ} \mathbf{9 . 5 0 3}$ de $\mathbf{2 3}$ de setembro de 1997. Institui o Código de Trânsito Brasileiro. Brasília, DF: Presidência da República, [1997]. Disponível em: http://www.planalto. gov.br/ccivil_03/leis/19503.htm. Acesso em: 16 abr. 2020.

BRASIL. Lei $\mathbf{n}^{\circ} \mathbf{1 0 . 4 0 6}$ de $\mathbf{1 0}$ de janeiro de 2002. Institui o Código Civil. Brasília, DF: Presidência da República, [2002]. Disponível em: http://www.planalto.gov.br/ ccivil_03/leis/2002//10406.htm. Acesso em: 16 abr. 2020.

BRASIL. Lei $\mathbf{n}^{\circ} \mathbf{1 2 . 4 5 2}$ de $\mathbf{2 1}$ de julho de 2011. Altera o art. 143 da Lei $n^{\circ}$ 9.503, de 23 de setembro de 1997, que "institui o Código de Trânsito Brasileiro", de modo a disciplinar a habilitação de condutores de combinações de veículos. Brasília, DF: Presidência da República, [2011].

Disponível em: http://www.planalto.gov.br/ccivil_03/_ Ato2011-2014/2011/Lei/L12452.htm\#art1. Acesso em: 21 abr. 2020.

BRAZIL OF GRID. Hidráulica do motorhome passo a passo. [S.I.], [2018?]. YouTube: Brazil Off Grid. Disponível em: https://youtu.be/XT5qgqODomg. Acesso em: 24 abr. 2020.

BRUNA, P. Habitação social no Brasil. Estudos Avançados, São Paulo, v.29, n.83, p. 317-323, jan./abr. 2015. Disponível em: http://www.scielo.br/pdf/ea/v29n83/01034014-ea-29-83-00317.pdf. Acesso em: 3 jan.2019. 
CASSULA, W. Kombi Motorhome $\mathbf{R} \mathbf{\$ 6 0 0 0 0}$. Curitiba, [201-]. Disponível em: https://veiculo.mercadolivre.com. br/MLB-1468109643-kombi-motorhome-_JM. Acesso em: 28 abr.2020.

CIRIACO, D. 20 fotos de Kombis adaptadas para motorhome que você vai pirar. [S.I.], 2018. Disponível em: https://www.viajali.com.br/kombi-adaptada-para-motorhome/amp/. Acesso em: 24 abr.2020.

CONSELHO NACIONAL DE TRÂNSITO. Resolução $\mathbf{n}^{\circ}$ 292 de 29 de agosto de 2008, com as alterações das Resoluções n 319/2009, n 384/2011, 397/2011 e 418/2012 e da Deliberação n¹29/2012. Dispõe sobre modificações de veículos previstas nos arts. 98 e 106 da Lei n 9503, de 23 de setembro de 1997, que instituiu o Código de Trânsito Brasileiro e dá outras providências. [S.I.]: ConseIho Nacional de Trânsito, [2008]. Disponível em: https:// infraestrutura.gov.br/images/Resolucoes/Consolidadas/ cons292.pdf. Acesso em: 22 abr. 2020.

CONSELHO NACIONAL DE TRÂNSITO. Resolução $n^{\circ}$ 743 de 12 de novembro de 2018. Estabelece requisitos técnicos para modificação ou transformação de veículos para motorcasa, assim como sua circulação e fiscalização. Diário Oficial da União: edição 225, seção 1, Brasília, DF, p. 288, 12 nov. 2018. Disponível em: http://www. in.gov.br/web/dou/-/resolucao-n-743-de-12-de-novembro- 
DE KOMBI POR AÍ. Banheiro box para Kombi. Vídeo 26: uma breve descrição do nosso box/chuveiro. [S.I.], [2017]. Canal do Youtube. Disponível em: https://www.youtube. $\mathrm{com} /$ watch? reload $=9 \& \mathrm{v}=3 \mathrm{LxcblakOTA}$. Acesso em: 27 maio. 2020.

GIL, A. C. Como elaborar projetos de pesquisa. 4. ed. São Paulo: Atlas, 2002.

GOOGLE. Google Forms. Google, 2019. Disponível em: https://docs.google.com/forms/u/0/. Acessado em: 15 nov. 2019.

GUTIERREZ, R. M. Casa móvel: experiência na região oeste do Paraná. 2008. Dissertação (Mestrado em Design e Arquitetura) - Faculdade de Arquitetura e Urbanismo, Universidade de São Paulo, São Paulo, 2008. Disponível em: https://teses.usp.br/teses/disponiveis/16/16134/ tde-16042010-095254/publico/Ricardo_Marques_Gutierrez_Dissertacao.pdf. Acesso em: 11 abr. 2020.

PALHARES, G. L. Transportes turísticos. São Paulo: Aleph, 2002, Apud In: SANTOS, T.B.S.; ALMEIDA, M.V.de. O Mercado de Veículos de recreação no Brasil. Turismo: Estudos \& Práticas, Mossoró, v.6, n.2, p. 121-149, jul./dez. 2017. Disponível em: http://periodicos.uern.br/index.php/ turismo/article/view/2741/1503. Acesso em: 07 abr. 2020 
RIO BIKE. Kombi-home - Montagem interna para uma

Kombi Motor-home. [S.I.], [2020?]. Disponível em: http:// www.riobikeshop.com.br/autos-trailer-e-motor-home/trailers-e-reboques/kombi-home-montagem--p . Acesso em: 28 maio 2020 .

\section{SALGUEIRO, A.F.W. Design de interiores em motorho-} mes. 2016. Monografia Especialização em Design de Interiores) - Departamento Acadêmico de Desenho Industrial, Universidade Tecnológica Federal do Paraná, Curitiba, 2016. Disponível em: http://repositorio.roca.utfpr.edu. br/jspui/bitstream/1/13923/1/CT_CEDIN_I_2016_05.pdf Acesso em: 07 abr. 2020.

SANTOS, T.B.S.; ALMEIDA, M.V.de. O Mercado de Veículos de recreação no Brasil. Turismo: Estudos \& Práticas, Mossoró, v.6, n.2, p. 121-149, jul./dez. 2017. Disponível em: http://periodicos.uern.br/index.php/turismo/article/ view/2741/1503. Acesso em: 07 abr. 2020.

SOLHA, K. T. A evolução do turismo no Brasil. In: REJOWSKI, M. (Org.). Turismo no percurso do tempo. 2.ed. São Paulo: Aleph, 2002. 